\title{
FORMAÇÃO AMBIENTAL DE ESTUDANTES DA ÁREA DA SAÚDE EM INSTITUIÇÃO DE ENSINO SUPERIOR
}

Janaína de Fátima dos Santos de Freitas-Anceles ${ }^{1}$

Aurélio Ferreira Borges ${ }^{2}$

José Aquino Junior ${ }^{3}$

Maria dos Remédios Freitas Carvalho Branco ${ }^{4}$

Andréa Lúcia Almeida de Carvalho ${ }^{5}$

Resumo: Avaliou-se o processo de formação de estudantes da área da saúde sobre a interface saúde e ambiente. Os dados foram coletados por meio de questionário validado e pesquisa documental junto a estudantes e coordenadores nos cursos de odontologia, medicina, enfermagem, educação física, nutrição e farmácia de uma instituição pública de ensino superior. Os resultados evidenciam que os estudantes não receberam formação ambiental e as grades curriculares de todos os cursos não contemplavam a Educação Ambiental. Considera-se a necessidade de incluir a interface saúde e ambiente nos processos pedagógicos de modo a preparar os futuros profissionais para o enfrentamento desta problemática.

Palavras-chave: Educação Ambiental; Saúde Ambiental; Meio Ambiente; Educação Superior.

\footnotetext{
1 Universidade Federal do Maranhão. E-mail: janafreitas05@gmail.com

2 Instituto Federal de Educação de Rondônia. E-mail: aferreiraborges@gmail.com

3 Universidade Federal do Maranhão. E-mail: zeaquinoju@gmail.com

4 Universidade Federal do Maranhão. E-mail: mrfcbranco@gmail.com

5 Universidade Federal do Maranhão. E-mail : andrea_alac@hotmail.com
} 


\section{Introdução}

Há desafios sócio ambientais, dentre os quais, a complexidade e diversidade existentes na problemática ambiental. Nesse contexto, as atividades profissionais devem se preocupar com os danos ambientais causados por elas, objetivando minimizar riscos ao ambiente e à saúde da população em geral (CORRÊA, 2005. p. 572). A partir disso, as profissões da saúde recebem destaque devido aos resíduos produzidos por suas atividades e, no contexto de preservação ambiental, suas práticas envolvem uma necessária articulação com a Educação e Formação Ambiental.

As discussões sobre Educação Ambiental (EA) começaram na década de 1960, quando emergiu a crise de ordem ambiental, devido à acentuada industrialização. A partir desta década, as preocupações a respeito de problemas ambientais passaram a não ser somente dos especialistas, mas também, de toda a sociedade (PALMA, 2005. p. 12). Na década de 1970, a Educação Ambiental, foi realmente foi concebida, quando ocorreu o primeiro grande encontro na promoção do debate ambiental. A Conferência das Nações Unidas sobre o Meio Ambiente Humano, realizada em Estocolmo (DECLARAÇÃO DE ESTOCOLMO, 1972).

Em 1977, na primeira Conferência Intergovernamental sobre Educação Ambiental, a Conferência de Tbilisi, ficou acordada a função, os objetivos e as principais diretrizes da EA, e que todas as pessoas deveriam ter esse direito. Em 1992, aconteceu a Conferência das Nações Unidas sobre Meio Ambiente e Desenvolvimento Humano (Conferência Rio-92). Como resultado, elaborou-se a Agenda 21, que considera as questões educacionais fundamentais para preservar os recursos naturais, fazendo nascer uma nova ética ambiental do desenvolvimento (AGENDA 21, 1992).

Vinte anos, após a Rio-92, ocorreu a Conferência das Nações Unidas sobre Desenvolvimento Sustentável (Rio+20), realizada em junho de 2012. Tal encontro gerou o documento "O futuro que queremos" que também ressalta a EA como fundamental para alcançar os objetivos de desenvolvimento sustentável.

No Brasil, desde a Constituição Brasileira de 1988 em seu Artigo 225, (BRASIL, 1988) já surgia o princípio da EA, sendo de competência do Poder Público promover a EA em todos os níveis de ensino e a conscientização pública para a preservação do meio ambiente. A importância da EA para o debate educacional se explicita, então, por ser formal e obrigatória constitucionalmente (SERPA, 2008, p. 34).

Para os parâmetros curriculares nacionais, a Educação Ambiental foi incluída através da Política Nacional de Educação Ambiental de 1999, (BRASIL, 1999). Os Ministérios da Educação e Meio Ambiente tem mutuamente contribuído para sua efetividade e permanência de forma transversal e multidisciplinar na educação formal brasileira, no entanto, sabe-se que sua eficiência e continuidade dependem de ações integradas e articuladas (JACOBI, 2003, p. 196).

Para alcançar os objetivos destas conferências ambientais, leis e outros documentos, em vista à Educação e Formação Ambiental, a Organização das Revbea, São Paulo, V. 11, № 4: 253-268, 2016. 
Nações Unidas (ONU) estabeleceu a Década da Educação para o Desenvolvimento Sustentável, compreendida entre janeiro de 2005 e dezembro de 2014 (BONIS; COSTA, 2009, p. 2108). Em conformidade com este empenho, um dos 253 itens relatados no documento "O futuro que queremos", resultante da Rio +20 , ressalta a importância da formação ambiental para o desenvolvimento sustentável.

235. Ressalta-se a importância de apoiar as instituições de ensino, em particular as de ensino superior dos países em desenvolvimento, para realizar pesquisas e inovações, em vista, a alcançar o desenvolvimento sustentável, especialmente no campo da educação, e desenvolver programas de qualidade e inovação, incluindo a formação em capacitação e conhecimenos empresariais, formação profissional, técnica e vocacional e aprendizagem ao longo da vida, visando sanar deficiências em habilidades e promover a realização dos objetivos nacionais de desenvolvimento sustentável (ASSEMBLEIA GERAL DAS NAÇÕES UNIDAS, 2012).

A partir disso, torna-se necessário o desenvolvimento de estratégias relacionadas à educação para o desenvolvimento sustentável. As soluções dependem de uma série de decisões tomadas em diferentes níveis do sistema, tais como, profissionais formados de maneira diferente daquela compartimentalizada existente nas universidades (CORRÊA, 2005, p. 572).

Como parte dessas estratégias, inclui-se um tipo de abordagem educacional que tem como primeira função a Educação Ambiental do público em geral, transmitindo conhecimentos gerais a todos os cidadãos, procurando fazer com que percebam os problemas ambientais em sua vida cotidiana e incentivando a adotar uma postura coerente. A segunda função é a formação ambiental de grupos profissionais ou sociais, tais como: engenheiros, arquitetos, médicos, dentistas, farmacêuticos, juristas, industriais etc., sensibilizando-os das consequências de sua atuação profissional para o meio ambiente. A terceira função é a formação de cientistas e profissionais que trabalham diretamente com o meio ambiente, como pesquisadores e engenheiros ambientais (PALMA, 2005, p. 13).

Para a função de formação de grupos profissionais, há que se diferenciarem os termos Educação Ambiental e Formação Ambiental.

A Educação Ambiental dirige-se ao grande público, levando as pessoas a uma compreensão global do meio ambiente (como um sistema de relações múltiplas). Porém, nem todos os setores da população podem contribuir de igual maneira para a solução da crise ambiental, uma vez que operam em contextos distintos e apresentam perfis sociais, culturais e econômicos diversos (GARCíA, 2001, p. 108). 
Já a Formação Ambiental, dirige-se a grupos profissionais restritos e capacita um setor profissional para o desempenho sustentável de sua atividade dentro da sociedade (BORGES, 2012, p. 245).

Com isso, a Formação Ambiental destina-se com grande alcance, em seus objetivos, às Instituições de Ensino Superior (IES), adequando cada profissão em bases de desenvolvimento sustentável, desde a sua formação.

Até a conferência Rio-92, as IES, praticamente, estiveram fora do palco da discussão sobre o desenvolvimento sustentável. A experiência, nesta conferência, trouxe uma lição clara: as universidades não devem se esquivar ao desafio. Devem usar suas forças combinadas para ajudar a resolver os problemas emergentes da sociedade global. Com isso, as IES assumem uma responsabilidade essencial na preparação das novas gerações para um futuro sustentável. Elas são um agente especialmente equipado para liderar o caminho e devem qualificar seus egressos, futuros tomadores de decisões, formando profissionais com responsabilidade ambiental (INTERNATIONAL ASSOCIATION OF UNIVERSITIES, 1993).

Dentro das IES, as graduações da área da saúde, merecem atenção, devido ao fato, de que as práticas da saúde abrangem uma gama de atividades e de interfaces que interagem não somente com o processo saúde-doença, como também com os aspectos e impactos ambientais (TAUCHEN; BRANDLI. 2006, p.505). Como exemplo, apreende-se, segundo Hiltz (2007, p.62), que o impacto ambiental anual da odontologia, nos Estados Unidos, revela-se em: 680 milhões de barreiras de plástico descartáveis; 1,7 bilhão de pacotes de esterilização; 28 milhões de litros de fixador; 4.800 .000 folhas de chumbo; 3,7 toneladas de resíduos de amálgama; 9 bilhões de galões de água (sistemas de vácuo de água) ou 360 litros de água/dia/consultório.

A partir disso, observa-se que os Resíduos de Serviços de Saúde (RSS) representam potenciais desafios para o meio ambiente, o que leva a uma preocupação cada vez maior com o gerenciamento desses resíduos em vista à preservação da biodiversidade (CORRÊA, 2005. p.572).

É possível que a não inserção da abordagem dos RSS no processo de formação dos futuros profissionais da saúde seja um aspecto importante para justificar o que acontece hoje em relação a esses resíduos no meio ambiente, como, o pouco engajamento no campo técnico/prático da saúde para reverter ou evitar o processo de degradação ambiental, sendo poucas as práticas observadas nas IES visando esse fim (CAMPONOGARA et al., 2008, p. 428).

Diante disso, parece ser relevante problematizar essa questão, num entendimento de que, para que sejam realizadas atitudes ambientalmente sustentáveis nos diferentes processos de atuação da atividade profissional das áreas da saúde, faz-se necessário um investimento em todos os profissionais da saúde, de forma a prepará-los e instrumentalizá-los para lidar com essa questão (CORRÊA, 2005. p. 572). 
Objetiva-se com este estudo, avaliar a capacitação dos estudantes da área da Saúde, de uma instituição de ensino superior, quanto à sua Formação Ambiental.

Com isso, busca-se demonstrar também, a necessidade da Formação Ambiental para os profissionais da Saúde dentro de uma permanente Educação Ambiental multidisciplinar.

\section{Metodologia}

Trata-se de um estudo descritivo realizado em instituição de ensino superior localizada no nordeste do país.

A Instituição em questão organiza-se em centros de ensino. Os cursos abordados por este estudo estão inseridos no Centro de Ciências Biológicas e da Saúde (CCBS). Optou-se em questionar os cursos da área da saúde com uma amostra do total de alunos do último ano em disciplinas teóricas, ou seja, os dois últimos períodos em sala de aula, totalizando 297 alunos.

O critério de seleção, para alunos do último ano, deveu-se ao fato de que, assim, os mesmos já teriam assistido a maioria das disciplinas do curso e, portanto, mais aptos a responder ao questionário.

A pesquisa foi aprovada pelo Comitê de Ética em Pesquisa da Universidade Federal do Maranhão (UFMA) sob o protocolo 23115-015063/201130.

\section{Instrumentos e coleta de dados}

Para o levantamento dos dados utilizou-se o Questionário de Formação Ambiental (QFA), desenvolvido por García (2001) e validado por Borges et al (2011), o qual se dividia nas seguintes áreas: a) temas sobre formação ambiental, recebidos em disciplinas na universidade; b) presença de trabalhos, exames, debates e práticas relacionadas ao meio ambiente, no curso de graduação; c) capacidades adquiridas por uma possível formação ambiental recebida na graduação; d) indicação do grau de formação ambiental recebido da universidade; e) indicação do peso atribuído, na formação universitária, para outras dimensões do conhecimento em relação às questões ambientais.

Solicitou-se que os universitários manifestassem seu grau de concordância ou discordância em uma escala intervalar tipo Likert para respostas psicrométricas (que buscam mensurar comportamentos), subdivididas nas opções de resposta um (1), (total discordância); dois (2) (discorda); três (3), (indeciso); quatro (4), (de acordo); e cinco (5), (totalmente de acordo), conforme Likert (1932).

A coleta de dados foi realizada no período de novembro de 2012 a janeiro de 2013 e sua administração foi feita no contexto da sala de aula. De modo geral, os estudantes levaram de 20 a 25 minutos para responder às perguntas. Para os processamentos estatísticos utilizou-se o software R 2..5.1 (R CORE TEAM, 2013).

revista brasileira educação ambiental 


\section{Estudo de fiabilidade}

Trata-se de estatística descritiva realizada para a obtenção de médias, medianas e desvio-padrão.

\section{Estudo de confiabilidade}

Realizado através do Teste de Cronbach, para o QFA, obtido da amostra de universitários. Esse teste analisa a consistência interna do questionário através de uma medida de confiabilidade que vai de 0 a 1 . Por convenção, quando o valor do alfa for igual ou superior a 0,60, a escala de medida é considerada aceitável.

Para a confiabilidade do questionário, realizou-se, também, o teste de Bartlett, para selecionar os fatores para a análise fatorial e determinar a variação total dos escores. Para garantir a correlação dos fatores, o valor deste teste deve ser $p<0,05$.

\section{Análise de Deviance}

Em vista à comparação de médias, foi realizada a Análise de Deviance, para identificar se ocorreram diferenças significativas detectadas na Formação Ambiental dos universitários. Para tal, utilizou-se um modelo linear generalizado considerando uma distribuição de Poisson. As diferenças foram consideradas significativas a $5 \%$ de probabilidade pelo teste de Chi-quadrado. A comparação entre as médias foi obtida utilizando contrastes de Tukey para modelos lineares generalizados, com o auxílio do software R 2.15.3.

\section{Análise Fatorial}

Por meio da Análise Fatorial, analisou-se a variabilidade total explicada, por meio do exame com rotação Varimax. Esta análise foi realizada com o propósito de agrupar as variáveis (questões) em fatores, de acordo com sua estrutura de correlação e tornar os dados observados mais facilmente interpretados. Com isso, seu objetivo foi definir o relacionamento entre as variáveis, de modo simples, e usar um número de fatores menor que o número original de variáveis. Como produto final dessa análise, encontraram-se as cargas fatoriais. Estas são a medida indireta do nível de importância de uma variável independente. Quanto maior for a carga fatorial, mais a variável se identifica com o que quer que seja o fator. 


\section{Resultados}

Do total da amostra (297), obteve-se um total de 269 questionários, sendo 32 alunos do curso de Educação Física, 50 alunos de Enfermagem, 42 alunos de Farmácia, 61 alunos de Medicina, 43 alunos de Nutrição e 41 alunos de Odontologia. A idade dos participantes variou entre 19 a 32 anos com uma média de 23 anos e desvio-padrão 2,16. Sendo $62,5 \%$ dos participantes do gênero feminino e $37,5 \%$ do gênero masculino.

\section{Estudo da fiabilidade}

A média $(2,29)$ e a mediana $(2,00)$, indicaram que o estilo de concordância entre os alunos admitiu valores próximos a dois (2), onde em uma escala de avaliação de 39 itens com opções de resposta de 1 a 5 , o valor mais frequente foi próximo a 2,00, com desvio padrão 1,12 (Tabela 1).

Tabela 1: Índice de fiabilidade para amostras dos seis cursos da área da saúde da UFMA.

\begin{tabular}{c|ccc}
\hline Curso & Média & Mediana & Desvio-padrão \\
\hline Ed. Física & 2,57 & 2,00 & 1,10 \\
Enfermagem & 2,29 & 2,00 & 1,04 \\
Farmácia & 2,50 & 2,00 & 1,05 \\
Medicina & 2,32 & 2,00 & 1,29 \\
Nutrição & 2,04 & 2,00 & 1,10 \\
Odontologia & 2,05 & 2,00 & 1,10 \\
\hline Geral & 2,29 & 2,00 & 1,12 \\
\hline
\end{tabular}

Fonte: Dados da pesquisa.

\section{Estudo da confiabilidade}

No que diz respeito à consistência interna os resultados revelaram um coeficiente alfa de Cronbach de 0,9233 para o total do QFA.

Foram selecionados oito (8) fatores pelo teste de Bartlett $(p<0,05)$ os quais foram responsáveis por $60,7 \%$ da variação total dos escores. $O$ teste de Bartlett apresentou valor de $\mathrm{p}=0,0001$.

\section{Avaliação fatorial}

A validade das variáveis foi determinada através da análise fatorial, com rotação ortogonal do tipo Varimax. Utilizando o critério para a retenção dos fatores com valores mínimos de 0,40, verificou-se existir identidade conceitual (BORGES, 2011, p. 37).

A variância explicada com índice $60,7 \%$ indica o impacto das correlações entre grupos de variáveis. A variância explicada foi maior no Fator 1, representado por 14 perguntas do QFA e 6 perguntas no Fator 2 . O valor $60,7 \%$ é a soma do impacto dos 8 fatores e indica a validade do QFA. O número de fatores oito (8), obtido, significa que são oito (8) grupos de correlações entre as variáveis. 
A análise fatorial determinou a carga fatorial $(\mu)$ de cada questão e definiuse conforme a Tabela 2 e da seguinte forma: as questões 3 e 15 não entraram em nenhum grupo, o que significa que as mesmas não estão relacionadas com as demais questões.

Tabela 2: Análise de componentes principais do QFA

\begin{tabular}{|c|c|c|c|c|c|c|c|c|c|}
\hline \multirow{2}{*}{\multicolumn{2}{|c|}{ № e síntese do item }} & \multicolumn{8}{|c|}{ Fatores } \\
\hline & & $\mathrm{F} 1$ & $\mathrm{~F} 2$ & F3 & $\mathrm{F} 4$ & F5 & F6 & $\mathrm{F} 7$ & F8 \\
\hline 1 & Conteúdo escolar & & & & & 0,5 & & & \\
\hline 2 & Aprendizagem ambiental & & & & & 0,6 & & & \\
\hline 3 & Informações passadas & & & & & & & & \\
\hline 4 & Crise do meio ambiente & & 0,6 & & & & & & \\
\hline 5 & Dimensão social & & 0,6 & & & & & & \\
\hline 6 & Análise leis ambientais & & 0,5 & & & & & & \\
\hline 7 & Contexto regional & & 0,5 & & & & & & \\
\hline 8 & Realidade ambiental & & 0,8 & & & & & & \\
\hline 9 & Estudo ambiental país & & 0,7 & & & & & & \\
\hline 10 & Trabalhos ambientais & & & & & & 0,6 & & \\
\hline 11 & Exames ambientais & & & & & & 0,5 & & \\
\hline 12 & Debates ambientais & & & & & & 0,5 & & \\
\hline 13 & Aulas práticas & & & & & & 0,5 & & \\
\hline 14 & Problemas da profissão & & & & & & & 0,5 & \\
\hline 15 & Efeitos da profissão & & & & & & & & \\
\hline 16 & Atuação da profissão & & & & 0,7 & & & 0,6 & \\
\hline 17 & Reflexão ambiental & & & & 0,8 & & & & \\
\hline 18 & $\begin{array}{c}\text { Percepção } \\
\text { complexidade }\end{array}$ & & & & 0,8 & & & & \\
\hline 19 & Solução problemas & & & & 0,8 & & & & \\
\hline 20 & $\begin{array}{l}\text { Biofísicos e sócio } \\
\text { culturais }\end{array}$ & & & & 0,7 & & & & \\
\hline 21 & Formação ambiental & & & & 0,5 & & & & \\
\hline 22 & Dimensão política & 0,5 & & & & & & & \\
\hline 23 & Dimensão jurídica & 0,4 & & & & & & & \\
\hline 24 & Dimensão histórica & 0,6 & & & & & & & \\
\hline 25 & Dimensão química & & & 0,9 & & & & & \\
\hline 26 & Dimensão física & & & 0,7 & & & & & \\
\hline 27 & Dimensão sanitária & & & 0,5 & & & & & \\
\hline 28 & Dimensão ecológica & 0,5 & & & & & & & \\
\hline 29 & Dimensão biológica & & & & & & & & 0,5 \\
\hline 30 & Dimensão filosófica & 0,7 & & & & & & & \\
\hline 31 & Dimensão antropológica & 0,3 & & & & & & & \\
\hline 32 & Dimensão geográfica & 0,7 & & & & & & & \\
\hline 33 & Dimensão sociológica & 0,8 & & & & & & & \\
\hline 34 & Dimensão urbanística & 0,7 & & & & & & & \\
\hline 35 & Dimensão econômica & 0,6 & & & & & & & \\
\hline 36 & Dimensão pedagógica & 0,8 & & & & & & & \\
\hline 37 & Dimensão tecnológica & 0,6 & & & & & & & \\
\hline 38 & Dimensão psicológica & 0,7 & & & & & & & \\
\hline 39 & Dimensão ética/moral & 0,6 & & & & & & & \\
\hline
\end{tabular}

Fonte: Dados da pesquisa. 
Fator um (1): Faz referência à relação entre as dimensões do conhecimento e a perspectiva de estudos relacionados ao meio ambiente. Inclui os itens $22,23,24,28,30,31,32,33,34,35,36,37,38$ e 39 que saturam entre $\mu=0,8$ e $\mu=0,4$.

Fator dois (2): Faz referência a possível contribuição do conhecimento sobre legislação e dimensão social abordada. Inclui os itens 4, 5, 6, 7, 8 e 9 que saturam entre $\mu=0,8$ e $\mu=0,5$.

Fator três (3): Faz referência à relação entre as dimensões Química, Física e Sanitária como inter-relacionadas com as perspectivas ambientais. Inclui os itens 25,26 e 27 que saturam entre $\mu=0,9$ e $\mu=0,5$.

Fator quatro (4): Faz referência às possíveis soluções dos problemas ambientais. Inclui os itens 17, 18, 19, 20 e 21 que saturam entre $\mu=0,8$ e $\mu=0,5$.

Fator cinco (5): Faz referência à profundidade com o qual o conteúdo é abordado. Inclui os itens um (1) e dois (2) que saturam em $\mu=0,5$ e $\mu=0,6$, respectivamente.

Fator seis (6): Faz referência à exposição do conteúdo de meio ambiente, abordado em sala de aula. Inclui os itens $10,11,12$ e 13 que saturam entre $\mu=0,6$ e $\mu=0,5$.

Fator sete (7): Faz referência à contribuição profissional que o conteúdo em aula fornece ao aluno. Inclui os itens 14 e 16 que saturam em $\mu=0,5$ e $\mu=0,6$, respectivamente.

Fator oito (8): Faz referência à disciplina de biologia na inter-relação com o meio ambiente. Inclui o item 29 que satura em $\mu=0,5$.

\section{Avaliação de deviance} pesquisados.

Não houve diferença significativa, de respostas, entre os cursos

Somente as variáveis oito (8) e 13 foram consideradas significativas, para os cursos de Nutrição e Odontologia (variável oito) e para o curo de Educação Física (variável 13), (Tabela 3). 
Tabela 3: Teste de Comparação das Médias de Concordância.

\begin{tabular}{|c|c|c|c|c|c|c|c|}
\hline Afirmações & Ed.Fís. & Enferm. & Farm. & Medic. & Nutriç. & Odont. & Prob. \\
\hline $\begin{array}{l}\text { 1. Conteúdos escolares relacionados ao } \\
\text { meio ambiente foram adequados. }\end{array}$ & 2.94 & 2.68 & 2.71 & 2.16 & 2.14 & 2.27 & 0.092 \\
\hline $\begin{array}{l}\text { 2. A profundidade da aprendizagem } \\
\text { universitária relacionada ao meio ambiente } \\
\text { foi adequada. }\end{array}$ & 2,50 & 2,20 & 2,40 & 2,03 & 1,72 & 1,98 & 0,165 \\
\hline $\begin{array}{l}\text { 3. Informações sobre o meio ambiente } \\
\text { relacionado a eventos ocorridos no passado } \\
\text { foram adequadas. }\end{array}$ & 2,31 & 2,38 & 2,81 & 2,39 & 2,23 & 2,29 & 0,608 \\
\hline $\begin{array}{l}\text { 4. Conhecimentos sobre a crise do meio } \\
\text { ambiente na atualidade foi adequado. }\end{array}$ & 2,72 & 2,42 & 2,45 & 2.21 & 1,91 & 2,05 & 0,193 \\
\hline $\begin{array}{l}\text { 5. Conhecimentos sobre a dimensão social } \\
\text { da problemática ambiental foi adequado. }\end{array}$ & 2,56 & 2,56 & 2,48 & 2,48 & 2,19 & 2,05 & 0,526 \\
\hline $\begin{array}{l}\text { 6. Análise sobre aspectos da legislação } \\
\text { relacionadas ao meio ambiente foi } \\
\text { adequado. }\end{array}$ & 2,03 & 2,00 & 2,05 & 2,20 & 1,79 & 2,00 & 0,833 \\
\hline $\begin{array}{l}\text { 7. Aplicação de conhecimentos sobre meio } \\
\text { ambiente no contexto regional foi adequado } \\
\text { à minha formação profissional. }\end{array}$ & 2,50 & 2,30 & 2,17 & 2,39 & 2,05 & 2,02 & 0,645 \\
\hline $\begin{array}{l}\text { 8. Estudos sobre a realidade ambiental } \\
\text { no Maranhão foram adequados. }\end{array}$ & $2,44 a$ & $1,94 a$ & $2,07 a$ & $2,36 a$ & $1,79 b$ & $1,58 b$ & $0,045^{\star}$ \\
\hline $\begin{array}{l}\text { 9. Estudos sobre a problemática ambiental } \\
\text { no Brasil foram adequados. }\end{array}$ & 2,44 & 2,10 & 2,19 & 2,25 & 1,93 & 1,71 & 0,281 \\
\hline $\begin{array}{l}\text { 10. Trabalhos sobre questões relacionadas } \\
\text { ao meio ambiente foram suficientes. }\end{array}$ & 2,34 & 2,06 & 2,29 & 2,16 & 1,72 & 1,88 & 0,334 \\
\hline $\begin{array}{l}\text { 11. Exames com perguntas relacionadas ao } \\
\text { meio ambiente foram corretamente } \\
\text { elaborados. }\end{array}$ & 1,94 & 2,00 & 2,10 & 2,18 & 1,65 & 1,75 & 0,412 \\
\hline $\begin{array}{l}\text { 12. Debates relacionados à problemática } \\
\text { ambiental foram utilizados nas disciplinas. }\end{array}$ & 2,41 & 2,32 & 2,10 & 2,10 & 1,74 & 1,73 & 0,161 \\
\hline $\begin{array}{l}\text { 13. Ocorreram aulas práticas com } \\
\text { características relacionadas ao meio } \\
\text { ambiente. }\end{array}$ & 3,00a & $1,96 \mathrm{~b}$ & $1,93 b$ & $1,80 b$ & $1,40 b$ & $1,46 b$ & $0,000^{*}$ \\
\hline $\begin{array}{l}\text { 14. Conhecer os problemas do meio } \\
\text { ambiente que estão relacionados ao curso } \\
\text { de graduação que frequento. }\end{array}$ & 2,63 & 2,38 & 2,79 & 2,38 & 2,44 & 2,20 & 0,608 \\
\hline $\begin{array}{l}\text { 15. Entender os efeitos de minha profissão } \\
\text { para contribuir com a solução dos } \\
\text { problemas ambientais. }\end{array}$ & 3,00 & 2,60 & 3,21 & 2,70 & 2,70 & 2,80 & 0,553 \\
\hline $\begin{array}{l}\text { 16. Saber atuar desde meu campo } \\
\text { profissional diante de problemas } \\
\text { ambientais. }\end{array}$ & 3,19 & 2,66 & 2,86 & 2,62 & 2,67 & 2,24 & 0,257 \\
\hline $\begin{array}{l}\text { 17. Reflexionar com critério sobre a crise do } \\
\text { meio ambiente. }\end{array}$ & 2,53 & 2,31 & 2,71 & 2,43 & 2,05 & 2,25 & 0,463 \\
\hline $\begin{array}{l}\text { 18. Perceber a complexidade dos } \\
\text { problemas ambientais. }\end{array}$ & 2,88 & 2,36 & 2,80 & 2,62 & 2,30 & 2,39 & 0,464 \\
\hline $\begin{array}{l}\text { 19. Pensar em possíveis soluções a } \\
\text { problemas ambientais concretos. }\end{array}$ & 2,63 & 2,38 & 3,00 & 2,40 & 2,07 & 2,29 & 0,131 \\
\hline $\begin{array}{l}\text { 20. Compreender o meio ambiente como } \\
\text { uma entidade complexa de processos } \\
\text { biofísicos e sócio culturais. }\end{array}$ & 2,78 & 2,50 & 3,02 & 2,79 & 2,51 & 2,34 & 0,413 \\
\hline $\begin{array}{l}\text { 21. O grau de formação ambiental que você } \\
\text { adquiriu na universidade. }\end{array}$ & 2,40 & 2,08 & 2,41 & 2,18 & 2,03 & 1,88 & 0,569 \\
\hline
\end{tabular}




\section{Discussão}

Esta pesquisa mostrou que os estudantes da área da saúde da instituição pesquisada não recebem formação ambiental durante sua graduação. Apesar de alguns alunos afirmarem receber instruções em Educação Ambiental, de forma geral, a formação ambiental não é percebida. Isto, verificado através do Questionário sobre Formação Ambiental, que apresentou índice de fiabilidade com média de 2,29 e mediana dois (2), o que significa que na escala de avaliação com opções de resposta de 1 a 5 , o valor mais frequente foi próximo a 2 (item que discorda das afirmações).

Os resultados revelaram o coeficiente alfa $(\alpha)$ de Cronbach igual a 0,9233. Isso indica, portanto, resultados que aprovam a adequada homogeneidade do questionário. Quanto mais próximo de um (1), mais confiável, consistente e conciso é o questionário (CRONBACH, 2004, p.12). Apesar de o QFA já ter sido validado por Borges et al. (2012), mostrou-se necessária sua revalidação, por esta pesquisa, pelo fato de a população em estudo, ser diferente da estudada por Borges et al. (2012).

No sentido de conhecer as dimensões subjacentes, a validade de construto foi determinada através da análise fatorial dos componentes principais. Foram obtidos oito (8) grupos de correlações entre as 39 variáveis.

O total da variância $(60,7 \%)$ obtida, considerando oito fatores, está dentro do intervalo (entre $60 \%$ e $65 \%$ ) e indica a confiabilidade do QFA e o impacto das correlações entre os grupos de variáveis. Logo, as informações recolhidas por ele devem ser consideradas importantes (SNYDER et al., 1996, p. 329). A verificação da adequação da amostra à análise fatorial, avaliada pelo Teste de esfericidade de Bartlett foi excelente $(p<0,05)$. Este valor, também, indica que as correlações entre as variáveis são significativas e, portanto, faz sentido o desenvolvimento da análise fatorial.

Para os cursos da área da saúde (Educação física, Enfermagem, Farmácia, Medicina, Nutrição e Odontologia), a variância explicada foi maior no Fator um (1), representado por 14 perguntas do QFA, o qual faz referência à relação entre as dimensões do conhecimento e a perspectiva de estudo relacionada ao meio ambiente presente na formação. De acordo com a Política Nacional de Educação Ambiental em seu Artigo 5², parágrafo I (BRASIL, 1999), são objetivos fundamentais da Educação Ambiental, o desenvolvimento de uma compreensão integrada do meio ambiente em suas múltiplas e complexas relações, envolvendo aspectos ecológicos, psicológicos, legais, políticos, sociais, econômicos, científicos, culturais e éticos. Neste fator, a questão sobre dimensão política e sua relação com o meio ambiente se apresentou com uma mediana de $12,5 \%$, indicando desprezível peso fatorial de sua atribuição na formação universitária.

A questão política deveria ser abordada em sala de aula explanando os órgãos e setores responsáveis, politicamente, pelas questões ambientais como o Programa das Nações Unidas para o Meio Ambiente (PNUMA), a Secretaria 
Especial de Meio Ambiente (SEMA), Conselho Nacional do Meio Ambiente (CONAMA), Agência Nacional de Vigilância Sanitária (ANVISA), dentre outros. Nesta questão, um graduando do curso de nutrição e dois do curso de enfermagem indicou peso de $100 \%$ da dimensão política em sua formação ambiental, o que pode refletir um interesse e busca individual nesse aspecto do conhecimento.

Seis perguntas ficaram representadas no Fator dois (2), o qual faz referência a uma possível contribuição do conhecimento sobre legislação e dimensão social abordada. Neste fator, verificou-se que, em sala de aula, a análise sobre aspectos da legislação relacionada ao meio ambiente não foi adequada (média 2,02), apesar de que, em todos os cursos houveram alunos que perceberam $75 \%$ de conteúdo sobre aspectos da legislação (5-farmácia, 3enfermagem, 5-medicina, 3-odontologia, 2-nutrição e 1-educação física). Observa-se que, para as profissões da saúde, torna-se imprescindível a educação sobre leis e regulamentações que tratam do gerenciamento de Resíduos de Serviços de Saúde (RSS).

Para tal, deve-se abordar a Lei 12.305 de agosto de 2010 (BRASIL, 2010) que instituiu a Política Nacional de Resíduos Sólidos, a qual se articula com a Política Nacional de Educação Ambiental (BRASIL, 1999) e, ainda, classifica os resíduos de saúde conforme definido em regulamentos estabelecidos pelos órgãos do Sistema Nacional do Meio Ambiente, através da Resolução № 358/2005 do CONAMA (CONAMA, 2005) e do Sistema Nacional de Vigilância Sanitária, através da RESOLUÇÃO da DIRETORIA COLEGIADA, RDC № 306/2004 (BRASIL, 2004); Estas resoluções tratam do gerenciamento dos Resíduos de Serviços de Saúde envolvendo desde a sua geração até sua destinação final. Um Programa de Gerenciamento pode ser capaz de minimizar ou até mesmo impedir os efeitos adversos causados pelos RSS, do ponto de vista sanitário, ambiental e ocupacional. Os Resíduos de Serviços de Saúde (RSS) representam potenciais desafios para o meio ambiente e os profissionais dessa área devem estar preparados para enfrentar tais desafios.

Além das questões ambientais gerais, que envolvem a área da saúde, são necessários estudos específicos em cada curso para averiguação dos problemas, específicos, que cada um pode gerar ao meio ambiente. Tal especificidade é o que leva à formação ambiental; e então, devem-se formular estratégias direcionadas à preservação do meio.

O fator oito (8) representou o menor grupo de perguntas (uma pergunta), significando que os currículos possuem dimensão biológica pouco expressiva, em sua inter-relação com o meio ambiente. Em se tratando de cursos da área da saúde, seria necessária uma maior intervenção envolvendo desde ações de biossegurança ocupacional até a ambiental amenizando os impactos causados pela profissão.

A partir da análise fatorial, apreende-se que os estudantes percebem ausência de formação ambiental nas estruturas curriculares, o que de fato ocorre, pois os currículos não contemplam a formação ambiental em suas grades. 
Ratificando esta ausência, os alunos discordam das afirmações sobre a ocorrência de exames e aulas práticas com características relacionadas ao meio ambiente, segundo a média de respostas em 1,96 e 1,88, respectivamente. Apenas nos cursos de educação física e medicina, dois alunos em cada curso, perceberam $100 \%$ de ocorrência de aulas práticas com características relacionadas ao meio ambiente, o que reflete interesses individuais em sua Educação Ambiental, mas não uma formação definida pela instituição.

Isso demonstra que os objetivos da Lei de Educação Ambiental (BRASIL, 1999) não estão sendo alcançados, nos cursos da saúde, por parte da instituição. Esta deveria promover a Educação Ambiental de maneira integrada aos programas educacionais que desenvolve. A formação ambiental deve ser ministrada de forma pontual, porém integrada a todo o período de formação dos indivíduos, garantindo sua Educação Ambiental.

Neste estudo, não houve diferença significativa na formação ambiental, ou sua ausência, entre os cursos pesquisados. Apenas duas variáveis foram consideradas significativas, segundo a avaliação de deviance.

A variável "Estudos sobre a realidade ambiental no Maranhão foram adequados" apresentou os cursos de Nutrição e Odontologia como os que mais discordam; e para a variável "Ocorreram aulas práticas com características relacionadas ao meio ambiente" o curso de Educação física foi o que menos discordou. Esses resultados diferem dos obtidos por Borges et al (2012, p.248), que também utilizou, como instrumento, o QFA, onde encontrou-se uma formação ambiental variável entre os cursos, por eles, pesquisados, apresentando melhor formação nos cursos de Tecnologia em gestão ambiental e Tecnologia em agronegócios que nos cursos de Tecnologia e produção de grãos, Zootecnia e Agronomia.

Conforme Palma (2005, p.59), analisando a percepção ambiental dos discentes da Universidade Federal do Rio Grande do Sul, alertou sobre a necessidade de efetivação de projeto de Educação Ambiental naquela instituição.

Consideramos que por meio da inserção da Formação ambiental nas instituições de ensino superior, destacando-se a área da saúde, a transformação seja possível, trabalhando com a ideia de interdisciplinaridade, complexidade, ética, solidariedade, cooperação, cidadania, a fim de que os sujeitos que compõem esses espaços acadêmicos também sejam transformadores críticos dessa realidade com que ainda hoje nos deparamos, ou seja, de degradação ambiental, que por sua vez afeta a sociedade como um todo.

Com tudo isso, acreditamos, também, que o desenvolvimento de ementas de disciplinas em formação ambiental seja um passo importante para o desenvolvimento dessas estratégias e deve ser elaborado e aplicado em todos os cursos e áreas do conhecimento enfatizando como a formação ambiental deve voltar-se para as necessidades de cada profissão. 


\section{Conclusão}

(2).

O QFA apresentou índice de fiabilidade com média de 2,29 e mediana dois

Os resultados revelaram o coeficiente alfa ( $\alpha$ ) de Cronbach igual a 0,9233.

Foram obtidos oito (8) grupos de correlações entre as 39 variáveis.

O total da variância obtida foi $60,7 \%$ e está dentro do intervalo entre $60 \%$ e $65 \%$, que indica a confiabilidade linguística e textual do QFA.

A variância explicada foi maior no Fator um (1), representado por 14 perguntas do QFA.

Um graduando do curso de nutrição e dois do curso de enfermagem, em suas respostas, indicaram peso fatorial de $100 \%$ na importância da dimensão política em sua formação ambiental.

Em sala de aula, a análise sobre aspectos da legislação relacionada ao meio ambiente não foi adequada (média 2,02).

O fator oito (8) representou o menor grupo de perguntas (uma pergunta), significando que os currículos possuem dimensão biológica pouco expressiva, em sua inter-relação com o meio ambiente.

Nos cursos de educação física e medicina, dois alunos em cada curso, perceberam $100 \%$ de ocorrência de aulas práticas com características relacionadas ao meio ambiente.

\section{Referências}

AGENDA $21 . \quad$ Relatório $1992 . \quad$ Disponível em:<www.crescentefertil.org.br/agenda21/index2.htm>. Acesso em: 19 nov. 2015.

ASSEMBLÉIA GERAL DAS NAÇÕES UNIDAS. O futuro que queremos. 2012. $123^{a}$ sesión plenária. 27 de julio de 2012. Disponível em: $<$ http://www.meioambiente.pr.gov.br/arquivos/File/agenda21/O Futuro que Quer emos.pdf >. Acesso em: 25 nov. 2015.

BONIS, M. de; COSTA, M. A. F. Educação em biossegurança e bioética: articulação necessária em biotecnologia. Ciência \& Saúde Coletiva, Rio de Janeiro, v. 14, n. 6, p. 2107-2114, dez, 2009.

BRASIL. Constituição (1988). Constituição da República Federativa do Brasil. Brasília: Senado, 1988. 168p.

BRASIL. Lei $n \cong 9.795$, de 27 de abril de 1999. Dispões sobre a Educação Ambiental, institui a Política Nacional de Educação Ambiental e dá outras providências. Diário Oficial da União, Brasília, 28 abr. 1999. Disponível em: <http://www.presidencia.gov.br>. Acesso em: 7 dez. 2015. 
BORGES. M.A.S. et al. Adaptação e validação do questionário quanto à formação ambiental. Revista eletrônica do Mestrado em Educação Ambiental. ISSN 1517-1256, Rio Grande do Sul, v. 26, janeiro a junho, 2011.

BORGES. M.A.S. et al. Formação ambiental dos universitários do Instituto Federal de Educação Goiano. Revista eletrônica do Mestrado em Educação Ambiental. ISSN 1517-1256, Rio Grande do Sul, v. 28, janeiro a junho, 2012.

BRASIL. Constituição (1988). Brasília, DF: Senado Federal, 1988.

BRASIL. Lei no 9.795, de 27 de abril de 1999. Dispõe sobre a Educação Ambiental, institui a Política Nacional de Educação Ambiental e dá outras providências. Diário Oficial [da] República Federativa do Brasil, Poder Executivo, Brasília, 28 abr. $1999 . \quad$ Disponível em: <http://www.planalto.gov.br/ccivil 03/leis//9795.htm>. Acesso em: 25 nov. 2015.

BRASIL. Resolução RDC no 306, de 7 de dezembro de 2004. Dispõe sobre o Regulamento Técnico para o gerenciamento de resíduos de serviços de saúde. Brasília, 7 de dezembro de $2004 . \quad$ Disponível em:<http://bvsms.saude.gov.br/bvs/saudelegis/anvisa/2004/res0306 07122004. html>. Acesso em: 30 set. 2016.

BRASIL. Lei $n^{\circ}$ 12.305, de 2 de agosto de 2010. Institui a Política Nacional de Resíduos Sólidos. Brasília, 2 de agosto de 2010. Disponível em:<http://www.planalto.gov.br.> Acesso em: 30 set. 2016.

CAMPONOGARA, S.; KIRCHHOF, A.L.; RAMOS, F.R. A systematic review about the scientific production with focus on the relation between health and environment. Ciência \& Saúde Coletiva. Rio de Janeiro, v. 13, n. 2, p. 427-439, 2008.

CONAMA. RESOLUÇÃO no 358, de 29 de abril de 2005. Dispõe sobre o tratamento e a disposição final dos resíduos dos serviços de saúde e dá outras providências. Brasília, 4 de maio de 2005 . Disponível em: <http://www.mma.gov.br/port/conama/legiabre.cfm?codlegi=462.> Acesso em: 30 set. 2016.

CORRÊA L.B.; LUNARDI, V.L.; CONTO, S.M.; GALIAZZI M.C. O saber resíduos sólidos de serviços de saúde na formação acadêmica: uma contribuição da Educação Ambiental. Interface - Comunicação, Saúde, Educação, v.9, n.18, p.571-84, set/dez, 2005.

CRONBACH, L.J. My current thoughts on coefficient alpha and successor procedures. Los Angeles: CSE/CRESST, 2004. (Studies CSE Report, 643). 2004.

DECLARAÇÃO DE ESTOCOLMO. In: Declaração da Conferência das Nações Unidas sobre o Meio Ambiente. Estocolmo, 1972. Disponível em: $<$ www.mma.gov.br/estruturas/agenda21/ arquivos/estocolmo.doc $>$. Acesso em: $19 / 11 / 2015$. 
GARCÍA, M.C. La ambientalización de la universidad. 2001. 610p. Tese (Doutorado em Educação) - Departamento de Didática, Universidade de Santiago de Compostela, Santiago de Compostela, 2001.

HILTZ, M. The Environmental Impact of Dentistry. www.cda-adc.ca/jcda/vol73/issue-1/59.html. JCDA - Journal of the Canadian Dental Association www.cda-adc.ca/jcda • February 2007, Vol. 73, No. 1

INTERNATIONAL ASSOCIATION OF UNIVERSITIES. Educations for Sustainable Development. 1993. Disponível em:<http://www.iauaiu.net/content/sustainable-development>. Acesso em: 24/11/2015.

JACOBI, P.R. Educação Ambiental, cidadania e sustentabilidade. Cadernos de Pesquisa, São Paulo, n. 118, p. 189- 205, mar, 2003.

LIKERT, R. A technique for the measurement of attitudes. Revista Archives of Psychology, New York, v. 22, n. 140, p. 1-55, 1932. Disponível em: <http://pt.wikipedia.org/wiki/Escala Likert>. Acesso em 24/11/2015.

PALMA, I.R. Análise da percepção ambiental como instrumento ao planejamento da Educação Ambiental. 2005. 83f. Dissertação (Mestrado em Engenharia de Minas, Metalúrgica e de Materiais) - Escola de Engenharia, Universidade Federal do Rio Grande do Sul, Rio Grande do Sul, 2005.

$R$ CORE TEAM. 2013. R: A language and environment for statistical computing. R Foundation for Statistical Computing, Vienna, Austria. ISBN 3900051-07-0. Disponível em: <http://www.R-project.org>. Acesso em: 24/11/2015.

SERPA, A.S. A Educação Ambiental na legislação brasileira e o seu contexto nos cursos de graduação de farmácia e odontologia da Universidade Federal do Ceará. 2008. 115f. Dissertação (Mestrado Profissional em Políticas Públicas e Gestão da Educação Superior) - Universidade Federal do Ceará, 2008.

SNYDER, C. R. et al. Development and validation of the State Hope Scale. Journal of Personality and Social Psychology, Arlington, v. 70, n. 2, p. 321335, Feb, 1996.

TAUCHEN, J.; BRANDLI, L.L. A gestão ambiental em instituições de ensino superior: modelo para implantação em campus universitário. Gestão e Produção, São Paulo, v.13, n.3, p. 503-515, 2006. 